\title{
NEW IRON CONTAINING HYBRID SILICATES FOR THE SELECTIVE REMOVAL OF ARSENIC OXYANIONS FROM CONTAMINATED WATER
}

\section{MEDHAT MOHAMED EL-MOSELHY ${ }^{A^{*}}$ AND MOHAMED S. THABET ${ }^{\mathrm{A}}$}

aChemistry Department, Faculty of Science, Al-Azhar University, Cairo, Egypt.

\begin{abstract}
A series of hybrid silicates containing iron oxides was synthesized via loading with hydrated iron oxide species (HFO) using a post precipitation mechanism from aqueous solution using different amounts of iron into the silica. The obtained materials were characterized by XRD, SEM, TEM, FTIR and low temperature nitrogen sorption. XRD analysis confirmed that HFO-Si was amorphous and iron oxide crystals in the silica cannot be detected due to both the lower size of HFO and the probability that occupying interstitial positions inside the silicate matrix. However, TEM image showed the presence of nano-sized HFO located inside the silicate matrix. The adsorption properties and selective efficiency of the synthesized materials were examf ined in the removal of $A s(V)$ and As (III) species from contaminated water under different experimental conditions as well as in the presence of competing anions. The increasing iron loading enhanced the arsenic adsorption capacity of HFO-Si and the maximum arsenic removal was found to be $623 \mathrm{mg} \mathrm{Fe} / \mathrm{g}$ silica after five successive loading times. The synthesized materials possess a unique adsorption capacity and their adsorption capacity reaches $303 \mathrm{mg} \mathrm{As/g} \mathrm{HFO-Si.} \mathrm{Adsorption} \mathrm{isotherm} \mathrm{data}$ for As $(V)$ on HFO-Si fitted well the Langmuir equation. In addition, the intraparticle diffusion models fitted the experimental kinetic data, suggesting that the rate limiting step of adsorption is most probably diffusion of arsenic ions into pores. Furthermore, the use of HFO-Si in column run and its easy regeneration makes it more sustainable to reuse several times to reduce the volume of arsenic laden waste.
\end{abstract}

Keywords: Arsenic adsorption; column run: HFO modification; silica gel

\section{INTRODUCTION}

Arsenic is one of the highest risky metals occurring as a natural element in the Earth's crust widely distributed in the environment. In humans, a long-term exposure of arsenic causes lung, liver, kidney, bladder and skin cancer. Ingestion of large doses of arsenic may be lethal and comparatively lower exposure levels can cause a variety of systemic effects including irritation of the digestive tract, vomiting and diarrhea, decreased production of erythrocytes and leukocytes, abnormal cardiac functions, blood vessel damage, liver and/or kidney damage and impaired nerve functions in the hands and feet ${ }^{[1-4]}$. Arsenic pollution of drinking water supplies was reported from over 70 countries, posing a serious health hazard to an estimated 150 million people worldwide ${ }^{[5,6]}$. International World Health Organization (WHO) and United States Environmental Protection Agency (EPA) and many local organizations made to reduce the arsenic threshold from 50 to $10 \mu \mathrm{g} \mathrm{L}^{-1}$ in the drinking water ${ }^{[7]}$.

Main arsenic removal techniques can be reported as follows: oxidation/precipitation, coagulation/electrocoagulation/co-precipitation, sorption and ion-exchange techniques, and mem- brane techniques. Many bioremediation techniques were used as well, but it has no enough effect on drinking water ${ }^{[8]}$. Adsorption techniques have been developed and getting more useful when an adsorbent for arsenic removal possesses certain characteristics such as high capacity, durability and high removal capacity. Recently, many materials have been used and studied as adsorbent for removal of As (III) and As (V) from water. In addition to commercial activated carbons ${ }^{[9]}$, several types of activated carbons were synthesized and used for the removal of arsenic from water/wastewater ${ }^{[10-12]}$. Besides, low cost adsorbents were used for the removal of arsenic. Reported adsorbents are given as follows: Agricultural products and by-products, industrial by-products/wastes such as chars and coals $^{[13,14]}$, red muds ${ }^{[15]}$, blast furnace slag ${ }^{[16,17]}$, $\mathrm{Fe}(\mathrm{III}) / \mathrm{Cr}$ (III) hydroxide waste ${ }^{[18]}$, fly ash ${ }^{[19]}$, soil ${ }^{[20]}$, sand ${ }^{[21-23]}$, clay minerals ${ }^{[24-26]}$, zeolites [27, 28], single or mixed oxides or hydroxides ${ }^{[29-}$ ${ }^{35]}$, hydrotalcites ${ }^{[36]}$, phosphates ${ }^{[37]}$, metal-based materials ${ }^{[38]}$, and biosorbents ${ }^{[39-42]}$.

In addition to aforementioned adsorbents, hybrid materials and its varieties have been studied for removal of metals or many organic contaminants from aqueous solutions ${ }^{[43-48]}$. The hybrid 
Medhat Mohamed et al .

material is characterized and employed in the removal of arsenic from aqueous solutions under the fixed-bed column ${ }^{[48]}$. In addition, the choice of hybrid silicates as an adsorbent has attracted the attention of researchers for arsenic removal after its modification with iron oxide ${ }^{[46,47]}$. Due to the unique characteristics in both physical and chemical structures, silica gel possesses many loftier assets that other peers can never replace, such as the adsorbability, selective adsorption, and thermal stability, chemical stability, scratch proof, dynamic resistance and durability. Therefore, the objective of this work is to generate a new silica gel material modified with higher contents of hydrated iron oxide (>600 mg Fe/gm silica) and characterize for high thermal stability, high durability, easy regeneration and reuse to achieve the selective removal of different arsenic species from contaminated water.

\section{EXPERIMENTAL}

\section{Synthesis of $\mathrm{HFO}-\mathrm{Si}$}

Silica gel with high-purity grade (pore size $60 \AA$, 70-230 mesh size) and $\mathrm{FeCl}_{3}$ (anhydrous, powder, $\geq 99$. 99\% trace metal basis) purchased from Sigma Aldrich were used for synthesize the iron loaded materials. Silica gel $(25 \mathrm{~g})$ was first treated with 5 (wt.) $\% \mathrm{NaOH}$ solution and kept under vigorous shaking for $5 \mathrm{~min}$ followed by washing with deionized (DI) water for several times till neutralization. The washed material was divided into 5 portions and then treated with different batches of $\mathrm{FeCl}_{3}$ (1-5 g). The HFO loaded materials were then washed with (DI) water and dried at the $100{ }^{\circ} \mathrm{C}$ overnight before thermal treatment at the $200{ }^{\circ} \mathrm{C}$ for 24 $\mathrm{h}$. The prepared samples were denoted as HFO-Si (1-5) according to the number of Fe loadings.

\section{Adsorbent characterization}

HFO-Si was characterized by scanning electron micrograph (SEM), (JEOL/ JSM-6610), provisioned with energy dispersive X-ray (EDX), (OXFORD INSTRUMENTS INCA XAct/51-ADD0013), to provide a complete map for the formed nanoparticles of HFO-Si. In addition, TEM analysis of the synthesized samples was performed using JEOL-2100.
The crystal structure of the synthesized HFO-Si was investigated using X-ray diffraction (XRD) on a Rigaku Smart Lab X-ray diffractometer using non-monochromotographic $\mathrm{Cu} \mathrm{K} \alpha 1$ radiation ( $40 \mathrm{kV}, 40 \mathrm{~mA}, \lambda=1.5)$. Scanning was in the range $5-65^{\circ} \mathrm{C}$ of $2 \theta$.

The specific surface area and micropore volume of the samples were measured using $\mathrm{N}_{2}$ adsorption-desorption (AUTOSORB 1C) at $-196^{\circ} \mathrm{C}$. Prior to adsorption, the samples were evacuated, heated up to $300^{\circ} \mathrm{C}$ and evacuated to a pressure of $1.3 \mathrm{~Pa}$ was reached. This condition was maintained overnight. The surface area, total pore volume and micropore volume were determined by multipoint BET, t-plot and DR (Dubinin-Radushkevic), respectively.

Infrared absorption measurements were carried out using a Fourier Transform Infrared (FTIR) spectrophotometer (Bruker Optics- Alpha). The FTIR spectra were obtained in the wavenumber range $450-4000 \mathrm{~cm}^{-1}$ using single bounce ATR with diamond crystal.

The content of loaded iron as well as initial and non-adsorbed concentrations of arsenic in supernatants was determined by atomic absorption spectroscopy (AAS) (GBC A 4382).

\section{Adsorption studies.}

The equilibrium batch adsorption experiments were carried out for $0.1 \mathrm{~g}$ of HFO-Si by shaking with $200 \mathrm{ml}$ volume containing 100 ppm of As for $24 \mathrm{~h}$ at room temperature. The supernatant was centrifuged prior to arsenic measurement with AAS. The effect of competing ions coexisting in the feed solution, such as sulfate $(120 \mathrm{mg} / \mathrm{L})$, silicate $(30 \mathrm{mg} / \mathrm{L})$ and phosphate $(10 \mathrm{mg} / \mathrm{L})$ was also evaluated during the column run.

Fixed-bed column runs were carried out using a glass column (11 $\mathrm{mm}$ in diameter), constantflow, stainless steel pump and an ISCO fraction collector (Fig. 1). An exhausted silica loaded with hydrated iron oxide (HFO) was regenerated using 5 (wt.) $\% \mathrm{NaOH}+3$ (wt.) $\% \mathrm{NaCl}$.

In order to investigate the nature and mechanism of arsenic adsorption with silica modified with HFO several models were applied such as 
New iron containing hybrid silicates for the selective removal

pseudo-first-order, pseudo-second-order and intra-particle diffusion [49]. The study of sorption kinetics of As (V) with HFO-Si was performed using the setup in (Fig. 2) HFO-Si was loaded within the stirrer cell, which was spun at 1500 rpm to cause a vigorous flow of the solution entering the cell from the bottom and leaving through the radial holes. The diffusional resistances in the liquid film were neglected because of the high rotational speed. Small samples (3 $\mathrm{ml})$ were periodically withdrawn from the solution $(1.0 \mathrm{~L})$ and analyzed.

The control of adsorption process using porous materials as adsorbent is governed by multi-steps such as mass transfer through the outer boundary layer film of liquid surrounding the adsorbent surface, diffusion through the internal pores of the solid adsorbent, and adsorption at the active sites on the surface. In order to examine the nature of the adsorption mechanism of arsenic with HFO-Si the experimental results were fitted to the Langmuir isotherm model, pseudo-second order and intraparticle diffusion models.

The Langmuir model essentially describes the monolayer type of adsorption. It is expressed as follows:

$$
q_{e}=\frac{q_{m} b C e}{1+b C e}
$$

where $\mathrm{q}_{\mathrm{m}}(\mathrm{mg} / \mathrm{g})$ is the maximum adsorption capacity and $b\left(\mathrm{~L}^{\mathrm{mg}} \mathrm{mg}^{-1}\right)$ is the Langmuir constant. $\mathrm{Ce}(\mathrm{mg} / \mathrm{g})$ is the concentration at equilibrium. The equation for the pseudosecond order kinetic model is as follows:

$$
\frac{d q_{t}}{d t}=\mathrm{k}\left(q_{e}-q_{t}\right)^{2}
$$

where $\mathrm{q}_{\mathrm{e}}$ and $\mathrm{q}_{\mathrm{t}}$ are the amounts of As adsorbed per unit of mass of the adsorbent at equilibrium and time $t$, respectively. A linearized form of pseudo-second order rate equation are expressed as follows:

$$
\frac{t}{q_{t}}=\frac{1}{K q_{e}{ }^{2}}+\frac{1}{q_{e}} t
$$

In addition, initial rate of adsorption is $\mathrm{h}$ :

$$
h=\mathrm{k} q_{e}^{2}
$$

The intraparticle diffusion model can be described as follows:

$$
q_{t}=k_{p} t^{\frac{1}{2}}+C
$$

where $\mathrm{k}_{\mathrm{p}}$ is the intra-particle diffusion rate constant ( $\mathrm{mg} \mathrm{g}^{-1} \mathrm{~min}^{-0.5}$ ) obtained from the slope and $\mathrm{C}$ is the adsorption constant obtained from the intercept.

The charge distributions of arsenic were analyzed by using the Mulliken population analysis. The binding energy of $\mathrm{P}$ and $\mathrm{Si}$ was estimated by the energetic difference between the total energy of P/Si-contained complex and that of free complex and $\mathrm{P} / \mathrm{Si}$. All calculations were accomplished by Gaussian 06 program ${ }^{[50]}$.

\section{RESULTS}

\section{Characterization of samples}

\section{$X R D$}

$\mathrm{X}$-ray diffraction patterns of parent silica gel and the HFO-Si samples with different HFO contents were depicted in (Fig. 3) The patterns obtained indicate that the synthesized materials possess an amorphous structure with the absence of any diffraction lines indicating the presence of $\mathrm{Fe}-\mathrm{O}$ species. The undetected HFO species may be due to both the lower size of HFO which lies below the detection limit of the instruments and the probability of its occupying interstitial positions in the silicate matrix. The finding is consistent with results of Zeng ${ }^{[46,47]}$.

\section{FTIR}

The FTIR spectra of silica gel and the HFOSi samples with different HFO content were illustrated in Fig. 4. The obtained data indicate that the parent silica gel exhibits, bands at 1142, $1054,965,793,546$ and $442 \mathrm{~cm}^{-1}$ that could be assigned to the different tetrahedral framework atoms vibrations in silicate structure. Furthermore, two kinds of vibrations are observed due to internal and external linkage of $\mathrm{SiO}_{4}$ structure assigned by the bands at 1142 and $442 \mathrm{~cm}^{-1}$ for internal vibration linkage and at 1054, 965, 793 and $546 \mathrm{~cm}^{-1}$ for external linkage vibrations in the silicate structure ${ }^{[51]}$. On the other hand, the absence of a characteristic absorbance band for Fe-O species in (Fig. 4) may be due to well-incorporated iron inside the matrix of silica.

\section{SEM}

The EDS layered image of the HFO-Si samples modified with HFO were illustrated in (Fig. 
Medhat Mohamed et al .

5a) The data obtained indicate that only a few moieties of the loaded iron (red dots) exist on the surface, however the rest amount is not viewed. This finding is supported by the EDX data, corresponding a lower percentage of iron. The only explanation is that the loaded iron is well dispersed into the matrix of silica.

The image of tunneling electron microscope (TEM) was represented in (Fig. 5b) The obtained data show the particle diameter distribution for the HFO-Si nanoparticles; the mean particle size was calculated as $12.5 \mathrm{~nm}$. Particle sizes are ranged from 4.0 to $20 \mathrm{~nm}$. Furthermore, the image reflects that the loaded $\mathrm{Fe}$ exists as dark spots inside silica particles, indicating that loaded iron is mainly located inside the silicate matrix with average sizes in nano size that could not detect by XRD.

\section{Surface area texturing}

Parent silica, HFO-Si(1), HFO-Si(2) and HFO-Si(3) exhibit type II isotherm with different upward deviation hysteresis loops which might confirm the porous nature of the surface before and after modification with HFO (Fig.6) The flatter region in the middle, lies in the range $\mathrm{P} / \mathrm{P}^{\circ}=0.1-0.4$ for silica gel and 0.1-0.8 in case of HFO-Si 1\&2, represents the formation of a monolayer. Furthermore, at very low pressures, the micro pores fill with nitrogen gas caused the beginning of the formation of monolayer at the first knee. However, multilayer formation occurred at low pressures and capillary condensation at the higher ones.

Further loading of HFO into silica gel as in sample HFO-Si (4) and HFO-Si (5) exhibits type IV isotherm with a shorter upward deviation hysteresis loop with HFO-Si (5) (at $\mathrm{P} / \mathrm{Po}=0.4$ $0.65)$ when compared with relatively longer hysteresis loop of HFO-Si (4) (at P/Po $=0.4-0.85)$. Furthermore, at lower pressures the sharp rise in the knee indicates a high surface area as depicted in Table 1.

BET surface area reveals that the parent silica gel possesses $190.3 \mathrm{~m}^{2} \mathrm{~g}^{-1}$ and upon loading HFO surface area is falling down to 81.9, 91.9 and $111.8 \mathrm{~m}^{2} \cdot \mathrm{g}^{-1}$ for HFO-Si(1), HFO-Si(2) and HFO-Si(3), respectively. In addition, the rising up of HFO loading to reach (4) and (5) times (HFO-Si(4) and HFO-Si(5) leads to a very high surface areas (426.6 and $\left.781.8 \mathrm{~m}^{2} . \mathrm{g}^{-1}\right)$ as depicted in Table 1. The obtained high surface area may indicate well spreading of HFO on the silica matrix to occupy interstitial matrix position, giving rise to the increase of surface area.

Pore volume calculations indicate that silica gel and HFO modified ones exhibit a different pore volume depending on the amount of loaded HFO. The data also indicate that HFO-Si(5) sample possesses the highest pore volume when compared with the others. Furthermore, the calculations of micropore volume indicate that the microporisty decreases with increase of iron content.

\section{Effect of iron content and $\mathrm{pH}$ on arsenic re- moval}

Silica gel modified with HFO possesses iron content in the range $25-623 \mathrm{mg} \mathrm{Fe} / \mathrm{g}$ silica as seen in (Fig 7) and HFO content of the silica increases with increasing iron loading.

(Fig. 8) illustrates the effect of iron content on the removal of arsenic. The data obtained reveal that the amount of arsenic removed increases with the increase of HFO content and reaches a maximum value (300 $\mathrm{mg} \mathrm{As} / \mathrm{g}$ HFO-Si) for HFO-Si(5) samples, indicating that the arsenic species is mostly adsorbed by HFO formed on silica gel as reported by Zeng ${ }^{[46]}$

Besides HFO content, $\mathrm{pH}$ is also a key factor controlling the removal of arsenic from contaminated water. The investigation of $\mathrm{pH}$ effects on the process of adsorption was carried out at different $\mathrm{pH}$ range (2-12) and illustrated in (Fig. 9) The removal efficiency of HFO-Si increased with the raising up of the $\mathrm{pH}$ up to 7.0. The removal efficiency of HFO-Si with further increase of $\mathrm{pH}(\mathrm{pH} \geq 11)$ in the alkaline medium decreased. The results are accordance with $\mathrm{Fe}(\mathrm{III})$-Si binary oxide adsorbents and hydrous ferric oxide reported in references [46, 47, 5256]. It means that the surface of hydrated iron oxide is negatively charged, resulting in electrostatic repulsion between the negatively charged surface sites and $\mathrm{HAsO}_{4}{ }^{2-[47,52,57]}$.

\section{Adsorption isotherms}


New iron containing hybrid silicates for the selective removal

The data represented in (Fig. 10) illustrate the relationship between the amount of arsenic adsorbed at equilibrium $\left(\mathrm{q}_{\mathrm{e}}\right)$ and equilibrium concentration $\left(\mathrm{C}_{\mathrm{e}}\right)$ of arsenic as a preliminary step for constructing the adsorption isotherms. The efficiency of silica loaded with HFO was investigated in the selective removal of arsenic from contaminated water. The process of arsenic adsorption was found to follow Langmuir isotherm with a maximum adsorption capacity (qm) of $300 \mathrm{mg} \mathrm{As} / \mathrm{g}$ HFO-Si at $\mathrm{pH}(8)$ as depicted in (Fig. 11) Furthermore, the estimated adsorption capacity toward arsenic is 5 times higher than the regular iron modified adsorbent at the same working experimental conditions as reported in references ${ }^{[45-48]}$.

\section{Fixed-bed column run}

Fixed-bed column run experiments were carried out to get the most suitable cycle conditions to evaluate the As (V) removal capacity of modified silica. (Fig. 12) illustrates the arsenic effluent histories for four separate column runs using the same conditions on parent and HFO modified silica. The data obtained indicate that parent silica cannot remove arsenic from contaminated water due to the earlier breakthrough after the start of the column run. However, upon modification with HFO a unique adsorption behavior has been observed and its removal efficiency was last for more than 24000 bed volumes. The high removal efficiency could be assigned the higher iron content (600 mg Fe/g silica gel) well dispersed inside the matrix of silica.

(Fig. 13) shows the effluent of arsenic for HFO-Si (6) with the high content of silicate in the presence of phosphate. The obtained data illustrate that the synthesized materials can remove arsenic effectively for nearly 24000 bed volumes before attaining the breakthrough even in the presence of high doses of silicate and phosphate ions.

\section{Sorption kinetics:}

\section{Interruption mechanism:}

The determination of adsorption mechanism was carried out using an interruption test during the fixed-bed column treatment run with HFO-Si (5) as shown in the green circles represented in
(Fig. 12) After 36000 BVs, the influent feed was stopped deliberately for $24 \mathrm{~h}$. After resuming the flow, the concentration of arsenic in the effluent decreased $40 \%(\leq 10 \mathrm{ppb})$ before it is commencing to rise up again to the level prior to the interruption.

\section{Intraparticle diffusion mechanism:}

From the experimental results (Fig. 14) it is clear that the relationship between $\mathrm{q}_{\mathrm{t}}$ and $\mathrm{t}^{0.5}$ exhibits multi-linear relation, indicating that adsorption process takes place in three steps. The first, sharper portion was attributed to the diffusion of adsorbates through the solution to the external surface of adsorbent, or the boundary layer diffusion of solute molecules. The second, the gradual adsorption stage occurs where intraparticle diffusion was rate limiting. The third portion was attributed to the final equilibrium stage for which the intraparticle diffusion started to slow down due to the extremely low adsorbate concentration left in the solution. Furthermore, the rate of removal might be limited by the size of adsorbate molecule, concentration of the adsorbate and its affinity to the adsorbent, diffusion coefficient of the arsenic ions in the bulk phase, the pore-size distribution of the adsorbent. As seen in (Fig. 14) the plots were not linear over the whole time range, implying that more than one process affected the adsorption. For different initial concentration, the adsorption of arsenic gave a similar pattern. The multiple natures of these plots could be explained by boundary layer diffusion and the intraparticle diffusion that gave further two linear portions. The slope of the linear portions indicates the rate of the adsorption that the lower slope corresponds to a slower adsorption process. This implied that the intraparticle diffusion of arsenic ions into pores was the rate-limiting step in the adsorption process on HFO-Si, particularly for long contact time periods $\left(8-16 \mathrm{~min}^{0.5}\right)$.

The kinetic of adsorption process was investigated and illustrated in (Fig. 15) Adsorption process was found in a good fitting with pseudosecond order. 
Medhat Mohamed et al .

Table 1. Variation of surface area and pore characteristics of silica by the iron loading

\begin{tabular}{lcccc}
\hline Sample & $\mathrm{S}_{\mathrm{BET}}{ }^{\mathrm{a}}\left(\mathrm{m}^{2} \cdot \mathrm{g}^{-1}\right)$ & $\mathrm{V}_{\text {Total }}{ }^{\mathrm{b}}\left(\mathrm{cm}^{3} \cdot \mathrm{g}^{-1}\right)$ & $\mathrm{V}_{\text {micro }}{ }^{\mathrm{c}}\left(\mathrm{cm}^{3} \cdot \mathrm{g}^{-1}\right)$ & $\mathrm{Dp}(\AA)$ \\
\hline $\mathrm{SiO}_{2}$ & 190.3 & 0.53 & 0.077 & 55.8 \\
$\mathrm{FeS} 1$ & 81.9 & 0.54 & 0.030 & 130.9 \\
$\mathrm{FeS} 2$ & 91.9 & 0.44 & 0.042 & 97.8 \\
$\mathrm{FeS} 3$ & 111.8 & 0.36 & 0.008 & 65.2 \\
$\mathrm{FeS} 4$ & 426.6 & 0.51 & 0.028 & 24.1 \\
$\mathrm{FeS} 6$ & 781.8 & 0.61 & 0.021 & 15.7 \\
\hline
\end{tabular}

a Multipoint BET method ; bVolume adsorbed at $\mathrm{p} / \mathrm{p} 0=0.99$.; cMicropore volume calculated by DR method

Table 2: Kinetic parameters for arsenic adsorption

\begin{tabular}{|c|c|c|c|c|}
\hline \multirow{2}{*}{$\begin{array}{c}\text { Concentration } \\
(\mathrm{ppm})\end{array}$} & \multicolumn{4}{|c|}{ Pseudo second order } \\
\cline { 2 - 5 } & $\mathrm{k}\left(\mathrm{g} \mathrm{mg}^{-1} \mathrm{~min}^{-1}\right)$ & $\mathrm{q}_{\mathrm{e}}\left(\mathrm{mg} \mathrm{g}^{-1}\right)$ & $\mathrm{h}\left(\mathrm{mg} \mathrm{g}^{-1} \mathrm{~min}^{-1}\right)$ & $\mathrm{R}^{2}$ \\
\hline 50 & 0.012 & 9.45 & 96.1 & 0.998 \\
\hline 75 & 0.011 & 11.95 & 226.79 & 0.998 \\
\hline 100 & 0.0043 & 17.45 & 401.3 & 0.998 \\
\hline
\end{tabular}

Table 3: Theoretical calculations by Gaussian software (50)

\begin{tabular}{|c|c|c|c|}
\hline \multirow[t]{2}{*}{ Symbol } & \multicolumn{2}{|c|}{ Mulliken charge } & \multirow{2}{*}{$\begin{array}{l}\text { Dipole moment } \\
\text { (state colunm) }\end{array}$} \\
\hline & Atom & Charge & \\
\hline \multirow{4}{*}{${ }^{-O}(3)=O(4)$} & $\mathrm{O}(1)$ & -1.06 & \multirow[t]{4}{*}{0.0017} \\
\hline & $\mathrm{O}(2)$ & -0.94 & \\
\hline & $\mathrm{O}(3)$ & -0.94 & \\
\hline & $\mathrm{O}(4)$ & -0.71 & \\
\hline \multirow{4}{*}{${ }^{12}={ }_{(3)^{-}}^{(2)}$} & $\mathrm{O}(1)$ & -0.9962 & \multirow[t]{4}{*}{0.0021} \\
\hline & $\mathrm{O}(2)$ & -0.9963 & \\
\hline & $\mathrm{O}(3)$ & -0.9962 & \\
\hline & $\mathrm{O}(4)$ & -0.9962 & \\
\hline \multirow{4}{*}{${ }_{(2) \mathrm{O}^{-}}^{(3)}$} & $\mathrm{O}(1)$ & -0.855 & \multirow[t]{4}{*}{2.25} \\
\hline & $\mathrm{O}(2)$ & -0.871 & \\
\hline & $\mathrm{O}(3)$ & -0.871 & \\
\hline & & & \\
\hline \multirow{2}{*}{$\stackrel{(2)}{\mathrm{O}}=\mathrm{As}-\mathrm{O}^{-(1)}$} & $\mathrm{O}(1)$ & -0.818 & \multirow[t]{2}{*}{4.01} \\
\hline & $\mathrm{O}(2)$ & -0.818 & \\
\hline
\end{tabular}


New iron containing hybrid silicates for the selective removal

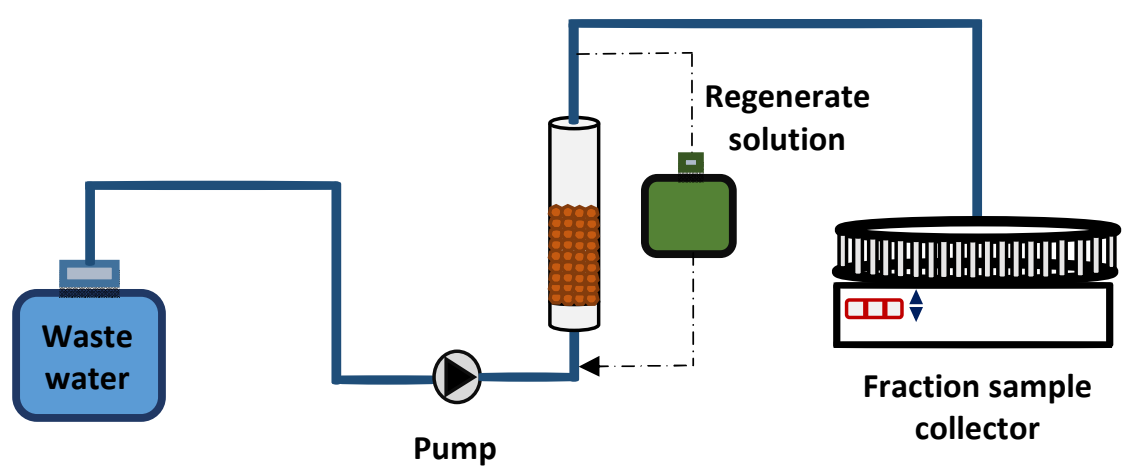

Fig. 1. The fixed bed column run of cation exchange material and the regeneration process of the material.

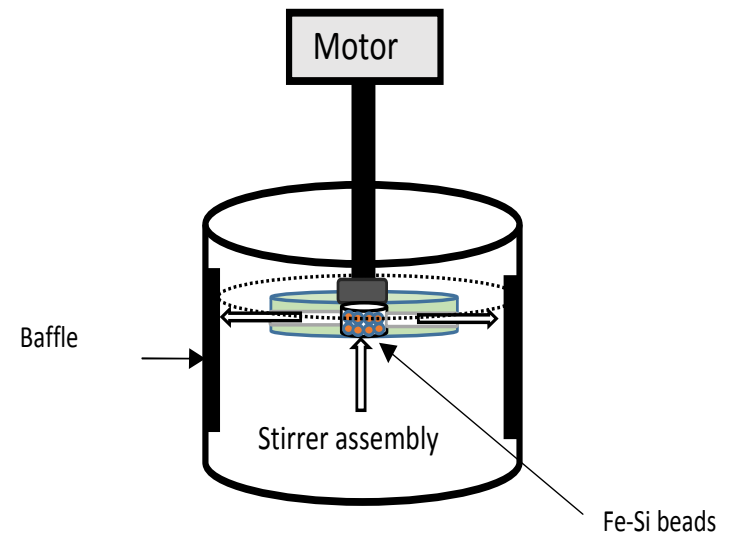

Fig. 2: Batch test apparatus for kinetics of arsenic adsorption

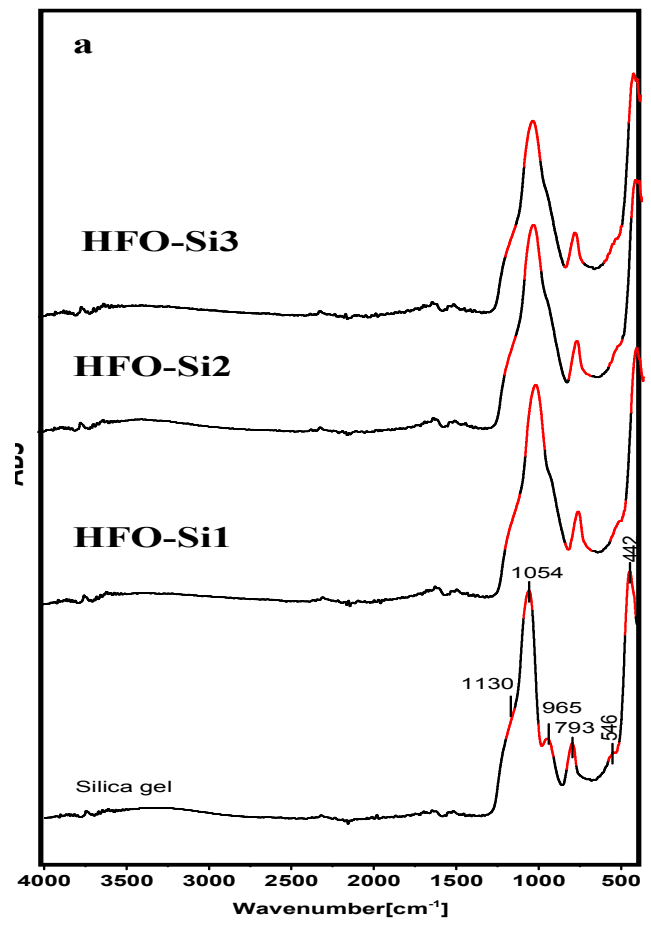

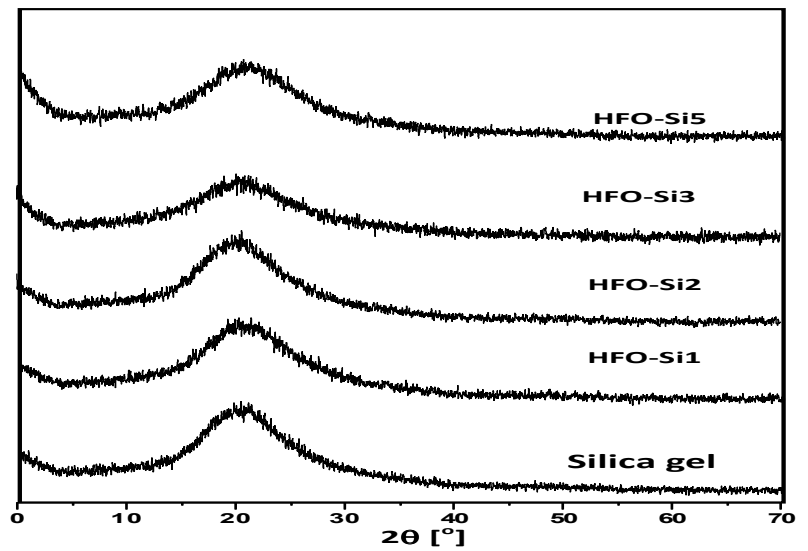

Fig. 3: XRD patterns

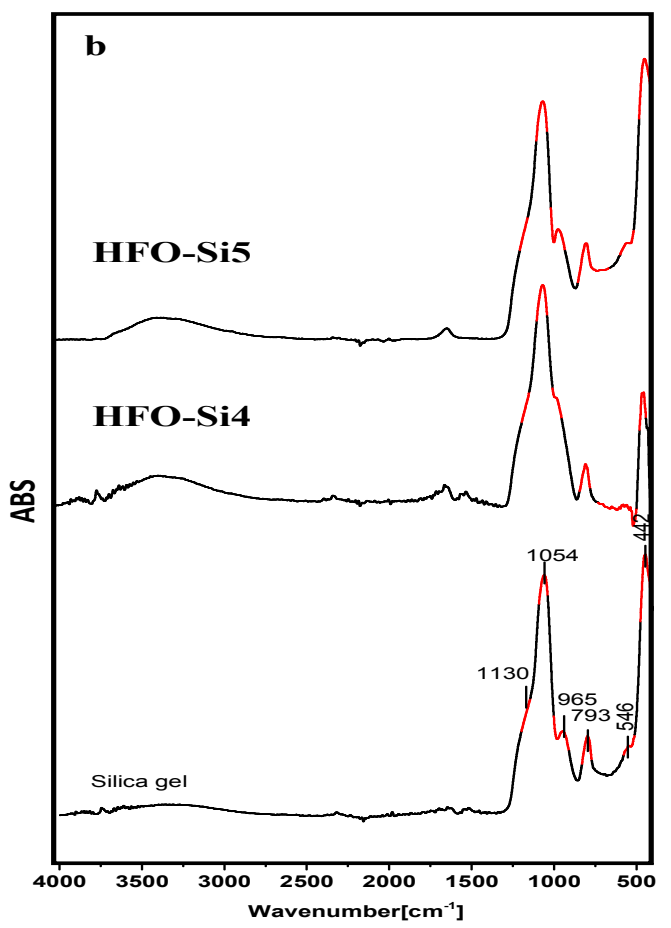

Fig. 4: FTIR spectra 
Medhat Mohamed et al .
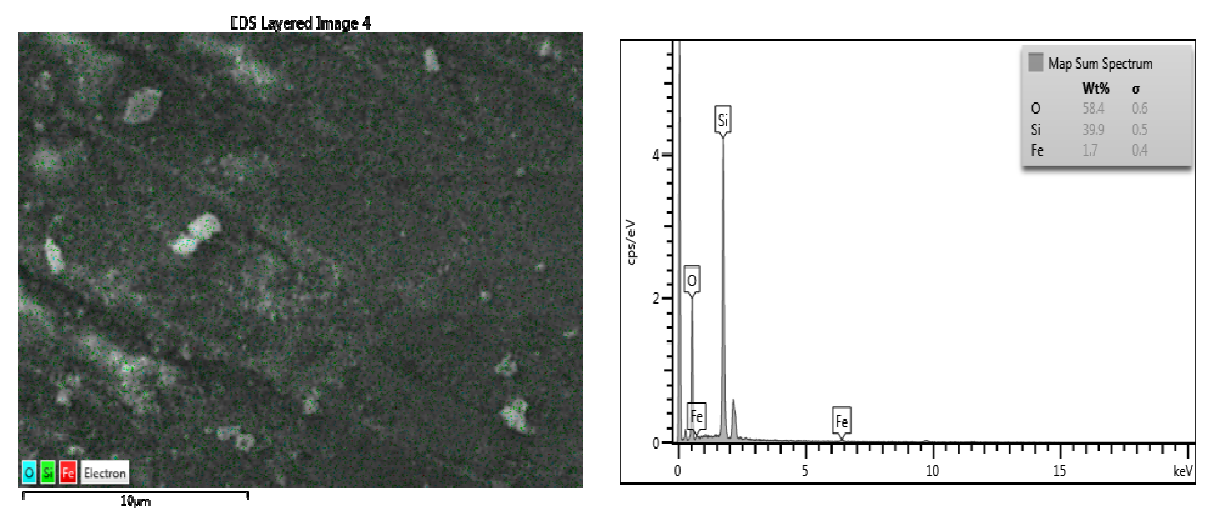

Fig. 5 a): SEM image and EDX mapping of HFO-Si(5)

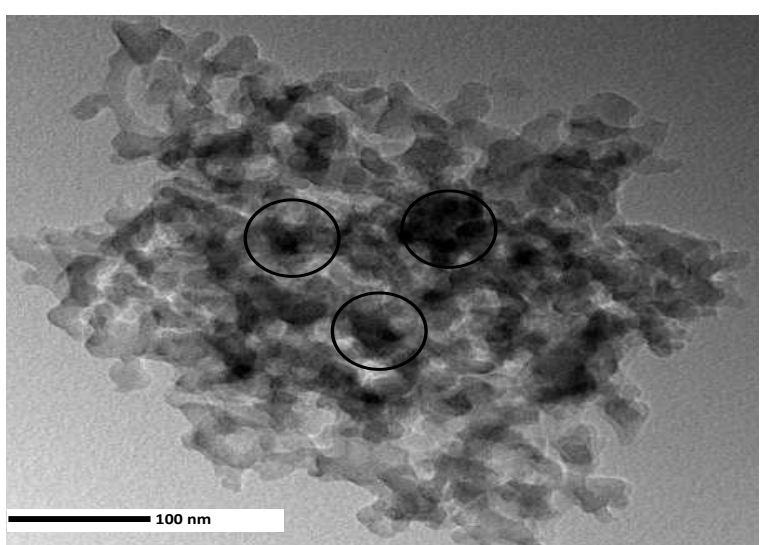

Fig. 5 b): Tunneling electron microscope (TEM) image of $\mathrm{HFO}-\mathrm{Si}(5)$
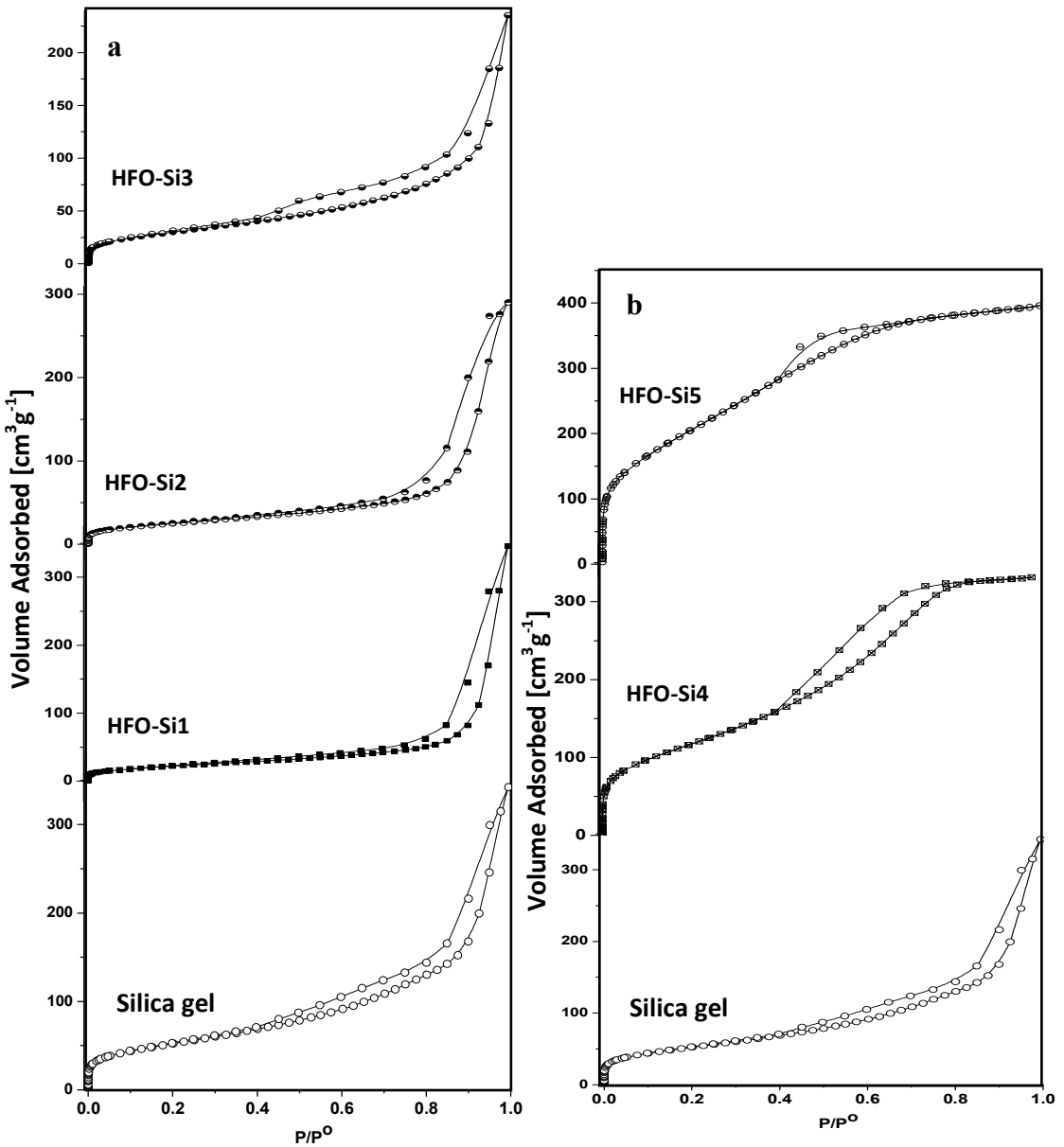

Fig. 6: Nitrogen adsorption-desorption isotherms 
New iron containing hybrid silicates for the selective removal

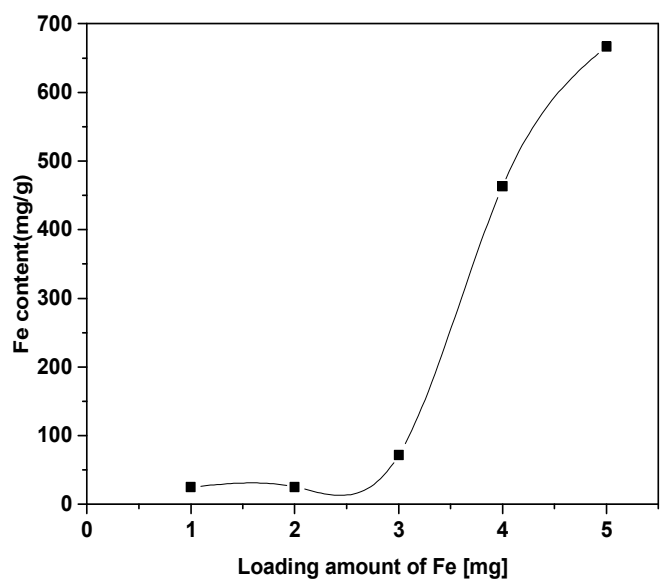

Fig. 7: Effect of loading times of Fe on Fe content of silica

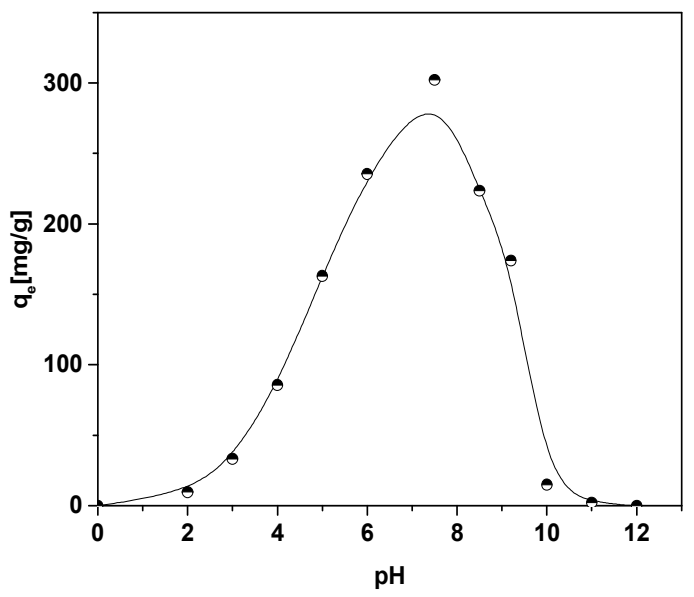

Fig. 9: Effect of pH on the adsorption of As o HFO-Si.

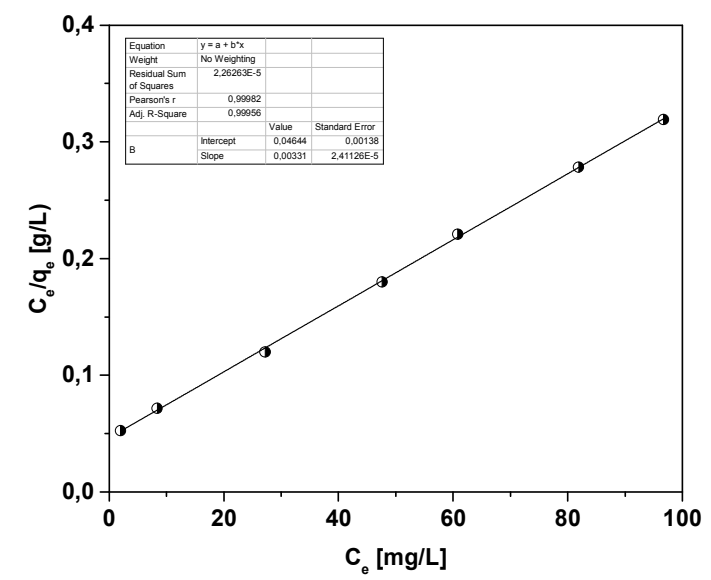

Fig. 11: Langmuir isotherm for the adsorption of As on HFO-Si.

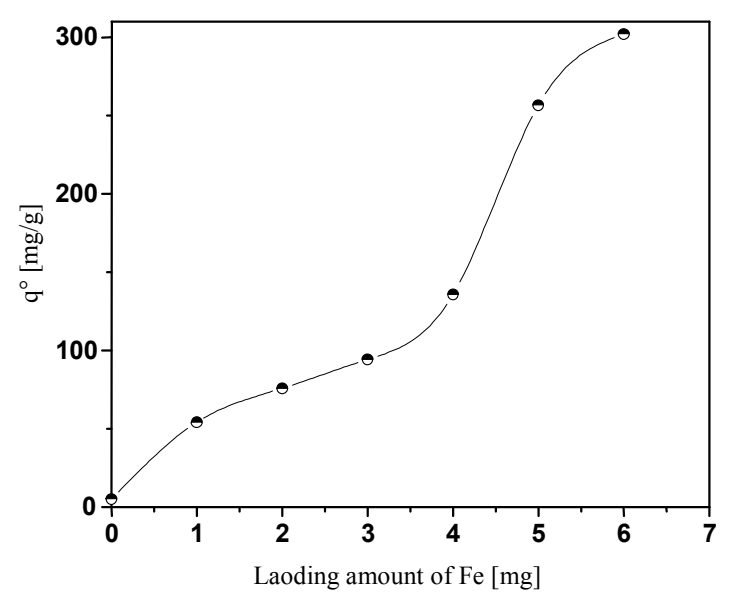

Fig. 8: Effect of Fe loading on the adsorption of As with HFO-Si.

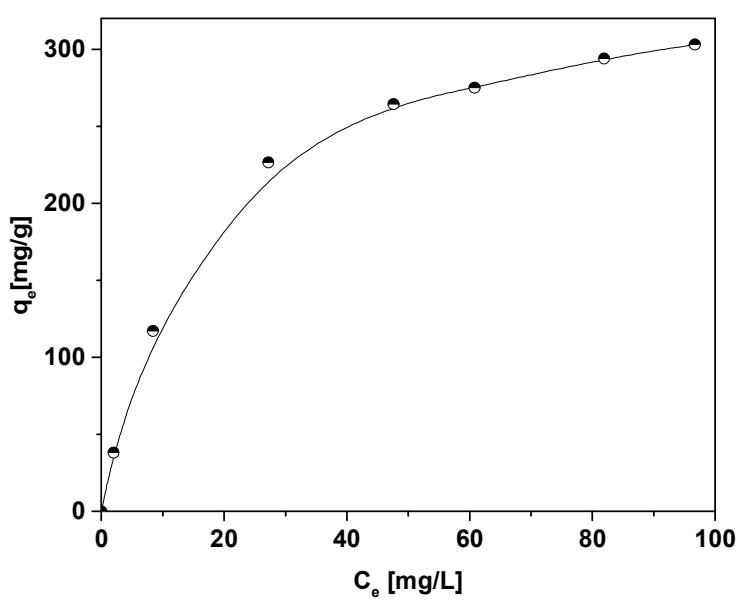

Fig. 10: Effect of initial concentration on the adsorbed amount of As on HFO-Si.

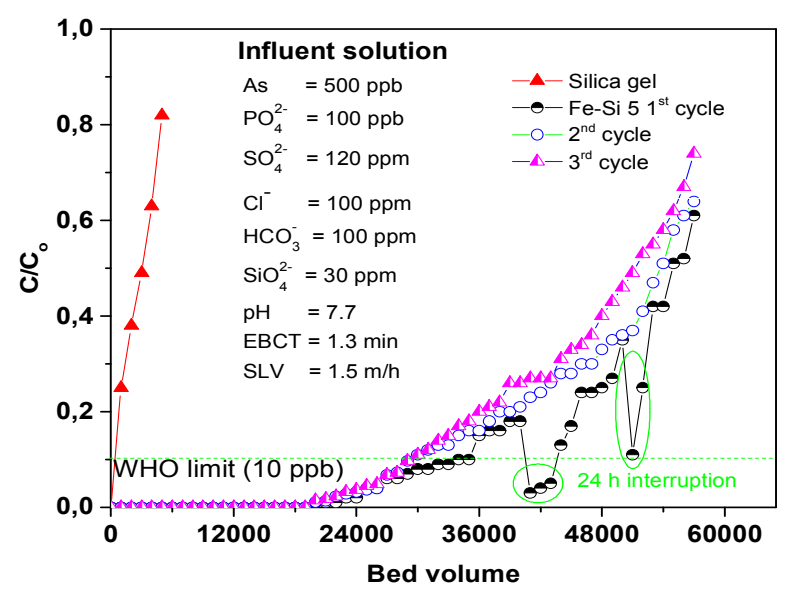

Fig. 12: Column run effluent history of As on HFO-Si. 
Medhat Mohamed et al .

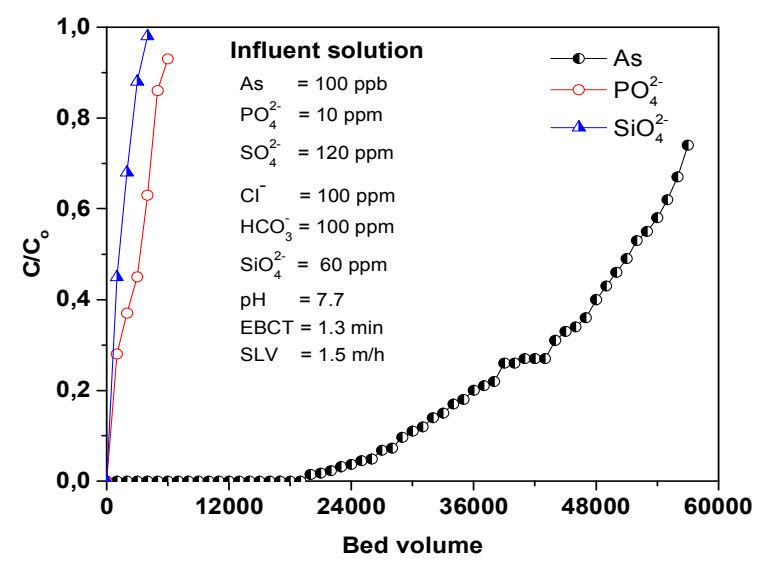

Fig. 13: Column run effluent history for the effect of competing ions on As removal using HFO-Si

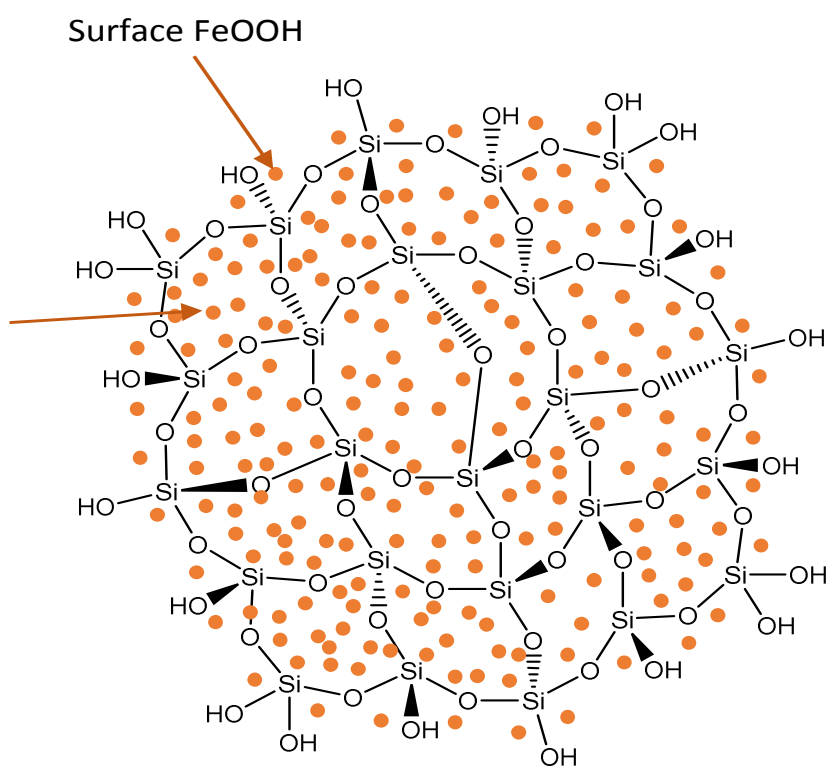

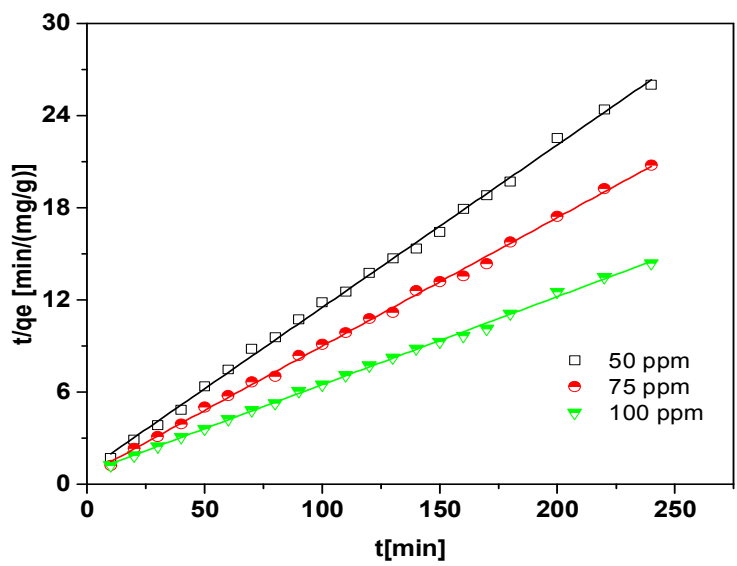

Fig. 14: Pseudo-second order sorption kinetics of As on HFO-Si.
Fig. 16: Proposed distribution of FeOOH species on silica gel surface

Fig. 17: Proposed mechanism for arsenic removal using HFO-Si materials 


\section{DISCUSSION}

New iron containing hybrid silicates for the selective removal

The modification of silica gel was carried out to swell and open the core shell of the silica gel particles, giving rise to the well dispersion of FeOOH particles not only on the surface but also deep inside the matrix of silica gel. Process of FeOOH loading indicates very high content of the loaded iron that reach $623 \mathrm{mg} \mathrm{Fe} / \mathrm{g}$ silica ${ }^{[46]}$.

Upon characterization of the synthesized materials using different techniques, no iron species were detected on the surface of HFO-Si samples with XRD and FTIR, which support the fact that iron was well dispersed inside the matrix of silica gel rather than the surface. On the other hand, surface examination with SEM-EDX tool indicated a few $\mathrm{FeOOH}$ presents on the surface while the rest of the loaded iron is not matched. This showed that $\mathrm{FeOOH}$ occupy interstitial positions inside the matrix of silica gel as represented in (Fig. 16).

Surface texturing using nitrogen adsorptiondesorption isotherms indicate very high surface area and high pore volume upon loading of $\mathrm{FeOOH}$ when compared with the parent silica gel. The increase in surface area and pore volume indicates that $\mathrm{FeOOH}$ can diffuse inside the silica gel core causing the elongation of that core to reach maximum iron loading $(623 \mathrm{mg} / \mathrm{g}$ silica). The elongation of core causes the stretching of pore volume to reach $0.614 \mathrm{~cm}^{3} \mathrm{~g}^{-1}[8,10]$.

Results validate that the selective removal of As (V) and As (III) mixture depends mainly on the amount of $\mathrm{FeOOH}$ present, $\mathrm{pH}$ of water and the maximum removal efficiency were observed with the highest $\mathrm{FeOOH}$ loaded sample HFO-Si 5 and $\mathrm{pH} \leq 8^{[46,47,52-56]}$. The higher adsorption capacity and selectivity of the synthesized samples are related with the incorporated $\mathrm{FeOOH}$ particles. The Lewis bases such as arsenates and arsenites can selectively be adsorbed through formation of inner and outer sphere complexes at the different adsorption sites of the synthesized materials ${ }^{[57]}$. On contrary to ion exchange resin, the modification of silica gel with $\mathrm{FeOOH}$ species shows that the distribution of $(\mathrm{FeOOH})$ inside the silica gel matrix is much greater than surface, giving rise to high adsorption capacity due to the absence of Donnan effect.
The application of the synthesized samples for large scale arsenic removal was carried out using column run experiments to get a clear idea about the efficiency of this materials as well as the effect of other competing species on the adsorption of arsenic ${ }^{[57]}$. Our study results depict the high efficiency of the synthesized samples that last for more than (24000) bed volume, indicating the high affinity and selectivity toward arsenic removal even in the presence of other competing anions ${ }^{[57]}$.

The estimated adsorption capacity towards modified adsorbent at the same working experimental conditions ${ }^{[45-48]}$. The unique adsorption capacity of the synthesized materials obtained from column run experiments could be assigned to the formation of inner sphere complex formed due to the Lewis acid- base (LAB) interaction between (HFO) and (Si-OH) particles, located on both surface and inside the pores ${ }^{[58]}$.

Interruption mechanism during the column run and intraparticle diffusion mechanism indicates that the adsorption process of different arsenic species involves multiple mass transfer steps containing mass transfer from the bulk of solution to the solid-liquid interface and intraparticle diffusion. The intraparticle diffusion step was considered as a predominant step due to the absence of Donnan effect that could hinder the process of adsorption due to electrostatic repulsion of ions with similar charges ${ }^{[59]}$. The sharp drop in the effluent arsenic concentration after restarting the column treatment run suggested that arsenic sorption on to HFO-Si(5) is mostly intraparticle diffusion ${ }^{[49,59]}$.

Results obtained from adsorption of different arsenic species was fitted with pseudo-second order kinetic models. Adsorption of As (V) and As (III) mixture follows the linearized transformation of pseudo-second order kinetic with different slopes depending on the initial concentration of arsenic used and correlation coefficient greater than 0.998. In addition, $\mathrm{q}_{\mathrm{e}}$ (Table 2) was calculated using the experimental results. This finding may support the assumption that the adsorption of different arsenic species follows the electrostatic interaction between the positively arsenic is 5 times higher than the regular iron 
Medhat Mohamed et al .

charged surface functional groups (HFO) and arsenic anions ${ }^{[57]}$.

The Gaussian calculations ${ }^{[50]}$ in Table 3 indicates that net Mulliken charge for arsenate species are much higher than phosphate and silicates, giving rise to the selective adsorption of arsenate species. Furthermore,

\section{CONCLUSION}

The modification process of silica gel was carried out using HFO particles via post precipitation technique in order to synthesize a new material with high selectivity toward arsenic removal. The synthesized materials were found to possess high iron content and high adsorption capacity when compared with many other adsorbents. Kinetic experiments and batch studies indicate the excellent adsorption behavior as well as selectivity for the removal of different arsenic species from contaminated water at near neutral $\mathrm{pH}$. The new synthesized materials had a unique physical and chemical properties and capable of removing different arsenic species from contaminated water upon applying it in column run since it lasts for more than 24000 bed volumes. The complete regeneration of the exhausted materials was accomplished successfully with 5 (wt.) $\% \mathrm{NaOH}+3$ (wt.) $\% \mathrm{NaCl}$.

\section{Acknowledgment}

I gratefully acknowledge the financial support given for this study by the research fund of Cumhuriyet University (M-585).

\section{REFERENCES}

[1] S. Muhammad, M.T. Shah, S. Khan, Arsenic health risk assessment in drinking water and source apportionment using multivariate statistical techniques in Kohistan region, northern Pakistan, Food and Chemical Toxicology, 48 (2010) 2855-2864.

[2] M.M. Rahman, R. Naidu, P. Bhattacharya, Arsenic contamination in groundwater in the Southeast Asia region, Environmental Geochemistry and Health, 31 (2009) 9-21.

[3] J.G. Thundiyil, Y. Yuan, A.H. Smith, C. Steinmaus, Seasonal variation of arsenic concentration in wells in Nevada, Environmental Research, 104 (2007) 367-373.

[4] S.H. Lamm, M.B. Kruse, Arsenic ingestion and bladder cancer mortality - What do the dose-response relationships suggest about, Hum Ecol Risk Assess, 11 (2005) 433-450.
[5] J.M. McArthur, P. Ravenscroft, D.M. Banerjee, J. Milsom, K.A. Hudson-Edwards, S. Sengupta, C. Bristow, A. Sarkar, S. Tonkin, R. Purohit, How paleosols influence groundwater flow and arsenic pollution: A model from the Bengal Basin and its worldwide implication, Water Resources Research, 44 (2008).1-30

[6] S. Sengupta, J.M. McArthur, A. Sarkar, M.J. Leng, P. Ravenscroft, R.J. Howarth, D.M. Banerjee, Do ponds cause arsenic-pollution of groundwater in the Bengal Basin? An answer from West Bengal, Environ Sci Technol, 42 (2008) 5156-5164.

[7] A. Celebi, B. Sengorur, B. Klove, Human health risk assessment of dissolved metals in groundwater and surface waters in the Melen watershed, Turkey, Journal of Environmental Science and Health Part a-Toxic/ Hazardous Substances \& Environmental Engineering, 49 (2014) 153-161.

[8] D. Mohan, C.U. Pittman, Arsenic removal from water/ wastewater using adsorbents - A critical review, Journal of Hazardous Materials, 142 (2007) 1-53.

[9] P. Navarro, F.J. Alguacil, Adsorption of antimony and arsenic from a copper electrorefining solution onto activated carbon, Hydrometallurgy, 66 (2002) 101-105.

[10] Z.M. Gu, J. Fang, B.L. Deng, Preparation and evaluation of GAC-based iron-containing adsorbents for arsenic removal, Environmental Science \& Technology, 39 (2005) 3833-3843.

[11] C.L. Chuang, M. Fan, M. Xu, R.C. Brown, S. Sung, B. Saha, C.P. Huang, Adsorption of arsenic(V) by activated carbon prepared from oat hulls, Chemosphere, 61 (2005) 478-483.

[12] B. Daus, R. Wennrich, H. Weiss, Sorption materials for arsenic removal from water: A comparative study, Water Research, 38 (2004) 2948-2954.

[13] D. Mohan, S. Chander, Removal and recovery of metal ions from acid mine drainage using lignite - A low cost sorbent, Journal of Hazardous Materials, 137 (2006) 1545-1553.

[14] M. Fan, W. Marshall, D. Daugaard, R.C. Brown, Steam activation of chars produced from oat hulls and corn stover, Bioresource Technology, 93 (2004) 103-107.

[15] H.S. Altundogan, S. Altundogan, F. Tumen, M. Bildik, Arsenic adsorption from aqueous solutions by activated red mud, Waste Management, 22 (2002) 357-363.

[16] F.S. Zhang, H. Itoh, Iron oxide-loaded slag for arsenic removal from aqueous system, Chemosphere, 60 (2005) 319-325.

[17] J.S. Ahn, C.M. Chon, H.S. Moon, K.W. Kim, Arsenic removal using steel manufacturing byproducts as permeable reactive materials in mine tailing containment systems, Water Research, 37 (2003) 2478-2488.

[18] K.S. Low, C.K. Lee, Chrome Waste as Sorbent for the Removal of Arsenic(V) from Aqueous-Solution, Envi- 
New iron containing hybrid silicates for the selective removal ronmental Technology, 16 (1995) 65-71.

[19] A. Mittal, L. Kurup, V.K. Gupta, Use of waste materials - Bottom Ash and De-Oiled Soya, as potential adsorbents for the removal of Amaranth from aqueous solutions, Journal of Hazardous Materials, 117 (2005) 171-178.

[20] H. Zhang, H.M. Selim, Kinetics of arsenate adsorption-desorption in soils, Environmental Science \& Technology, 39 (2005) 6101-6108.

[21] B. Petrusevski, S.K. Sharma, F. Kruis, P. Omeruglu, J.C. Schippers, Family filter with iron-coated sand: solution for arsenic removal in rural areas, 3rd World Water Congress: Drinking Water Treatment, 2 (2002) 127-133.

[22] C.Y. Jing, S.Q. Liu, M. Patel, X.G. Meng, Arsenic leachability in water treatment adsorbents, Environmental Science \& Technology, 39 (2005) 5481-5487.

[23] M. Vithanage, W. Senevirathna, R. Chandrajith, R. Weerasooriya, Arsenic binding mechanisms on natural red earth: A potential substrate for pollution control, Science of the Total Environment, 379 (2007) 244-248.

[24] Y. Arai, D.L. Sparks, J.A. Davis, Arsenate adsorption mechanisms at the allophane - water interface, Environmental Science \& Technology, 39 (2005) 2537-2544.

[25] P. Lakshmipathiraj, B.R. Narasimhan, S. Prabhakar, G.B. Raju, Adsorption of arsenate on synthetic goethite from aqueous solutions, Journal of Hazardous Materials, 136 (2006) 281-287.

[26] G.P. Gillman, A simple technology for arsenic removal from drinking water using hydrotalcite, Science of the Total Environment, 366 (2006) 926-931.

[27] K.B. Payne, T.M. Abel-Fattah, Adsorption of arsenate and arsenite by iron-treated activated carbon and zeolites: Effects of $\mathrm{pH}$, temperature, and ionic strength, Journal of Environmental Science and Health Part aToxic/Hazardous Substances \& Environmental Engineering, 40 (2005) 723-749.

[28] Y.H. Xu, T. Nakajima, A. Ohki, Adsorption and removal of arsenic $(V)$ from drinking water by aluminumloaded Shirasu-zeolite, Journal of Hazardous Materials, 92 (2002) 275-287.

[29] M. Badruzzaman, P. Westerhoff, D.R.U. Knappe, Intraparticle diffusion and adsorption of arsenate onto granular ferric hydroxide (GFH), Water Research, 38 (2004) 4002-4012

[30] S. Bang, M. Patel, L. Lippincott, X.G. Meng, Removal of arsenic from groundwater by granular titanium dioxide adsorbent, Chemosphere, 60 (2005) 389-397.

[31] T.F. Lin, J.K. Wu, Adsorption of arsenite and arsenate within activated alumina grains: Equilibrium and kinetics, Water Research, 35 (2001) 2049-2057.

[32] T. Nakajima, Y.H. Xu, Y. Mori, M. Kishita, H. Takanashi, S. Maeda, A. Ohki, Combined use of pho- tocatalyst and adsorbent for the removal of inorganic arsenic(III) and organoarsenic compounds from aqueous media, Journal of Hazardous Materials, 120 (2005) 75-80.

[33] M. Pena, X.G. Meng, G.P. Korfiatis, C.Y. Jing, Adsorption mechanism of arsenic on nanocrystalline titanium dioxide, Environmental Science \& Technology, 40 (2006) 1257-1262.

[34] A.C.Q. Ladeira, V.S.T. Ciminelli, Adsorption and desorption of arsenic on an oxisol and its constituents, Water Research, 38 (2004) 2087-2094.

[35] C.M. Su, R.W. Puls, In situ remediation of arsenic in simulated groundwater using zerovalent iron: Laboratory column tests on combined effects of phosphate and silicate, Environmental Science \& Technology, 37 (2003) 2582-2587.

[36] Y. Kiso, Y.J. Jung, T. Yamada, M. Nagai, K.S. Min, Removal properties of arsenic compounds with synthetic hydrotalcite compounds, Leading-Edge Technology 2005 - Water Treatment, 5 (2005) 75-81.

[37] W. Lenoble, C. Laclautre, W. Deluchat, B. Serpaud, J.C. Bollinger, Arsenic removal by adsorption on iron(III) phosphate, J Hazard Mater, 123 (2005) 262268.

[38] D.F. Martin, L. O’Donnell, B.B. Martin, R. Alldredge, Removal of aqueous arsenic using iron attached to immobilized ligands (IMLIGs), Journal of Environmental Science and Health Part a-Toxic/Hazardous Substances \& Environmental Engineering, 42 (2007) 97-102.

[39] C.C. Chen, Y.C. Chung, Arsenic removal using a biopolymer chitosan sorbent, Journal of Environmental Science and Health Part a-Toxic/Hazardous Substances \& Environmental Engineering, 41 (2006) 645-658.

[40] D. Pokhrel, T. Viraraghavan, Arsenic removal from an aqueous solution by a modified fungal biomass, Water Research, 40 (2006) 549-552.

[41] M.N. Haque, G.M. Morrison, G. Perrusquia, M. Gutierrez, A.R. Aguilera, I. Cano-Aguilera, J.L. GardeaTorresdey, Characteristics of arsenic adsorption to sorghum biomass, Journal of Hazardous Materials, 145 (2007) 30-35.

[42] M. Srivastava, L.Q. Ma, J.A.G. Santos, Three new arsenic hyperaccumulating ferns, Science of the Total Environment, 364 (2006) 24-31.

[43] B.J. Gao, Y.C. Gao, Y.B. Li, Preparation and chelation adsorption property of composite chelating material poly(amidoxime)/SiO2 towards heavy metal ions, Chem Eng J, 158 (2010) 542-549.

[44] E.B. Simsek, D. Duranoglu, U. Beker, Heavy Metal Adsorption by Magnetic Hybrid-Sorbent: An Experimental and Theoretical Approach, Sep Sci Technol, 47 (2012) 1334-1340.

[45] E. Repo, J.K. Warchol, A. Bhatnagar, M. Sillanpaa, 
Heavy metals adsorption by novel EDTA-modified chitosan-silica hybrid materials, J Colloid Interf Sci, 358 (2011) 261-267.

[46] L. Zeng, A method for preparing silica-containing iron(III) oxide adsorbents for arsenic removal, Water Res, 37 (2003) 4351-4358.

[47] L. Zeng, Arsenic adsorption from aqueous solutions on an Fe(III)-Si binary oxide adsorbent, Water Qual Res J Can, 39 (2004) 267-275.

[48] C.M. Iesan, C. Capat, F. Ruta, I. Udrea, Evaluation of a novel hybrid inorganic/organic polymer type material in the Arsenic removal process from drinking water, Water Res, 42 (2008) 4327-4333.

[49] X.J. Hu, J.S. Wang, Y.G. Liu, X. Li, G.M. Zeng, Z.L. Bao, X.X. Zeng, A.W. Chen, F. Long, Adsorption of chromium (VI) by ethylenediamine-modified crosslinked magnetic chitosan resin: Isotherms, kinetics and thermodynamics, J Hazard Mater, 185 (2011) 306-314.

[50] G.W.T. M. J. Frisch, H. B. Schlegel, G. E. Scuseria, M. A. Robb, J. R. Cheeseman, J. A. Montgomery, Jr., T. Vreven, K. N. Kudin, J. C. Burant, J. M. Millam, S. S. Iyengar, J. Tomasi, V. Barone, B. Mennucci, M. Cossi, G. Scalmani, N. Rega, G. A. Petersson, H. Nakatsuji, M. Hada, M. Ehara, K. Toyota, R. Fukuda, J. Hasegawa, M. Ishida, T. Nakajima, Y. Honda, O. Kitao, H. Nakai, M. Klene, X. Li, J. E. Knox, H. P. Hratchian, J. B. Cross, C. Adamo, J. Jaramillo, R. Gomperts, R. E. Stratmann, O. Yazyev, A. J. Austin, R. Cammi, C. Pomelli, J. W. Ochterski, P. Y. Ayala, K. Morokuma, G. A. Voth, P. Salvador, J. J. Dannenberg, V. G. Zakrzewski, S. Dapprich, A. D. Daniels, M. C. Strain, O. Farkas, D. K. Malick, A. D. Rabuck, K. Raghavachari, J. B. Foresman, J. V. Ortiz, Q. Cui, A. G. Baboul, S. Clifford, J. Cioslowski, B. B. Stefanov, G. Liu, A. Liashenko, P. Piskorz, I. Komaromi, R. L. Martin, D. J. Fox, T. Keith, M. A. Al-Laham, C. Y. Peng, A. Nanayakkara, M. Challacombe, P. M. W. Gill, B. Johnson, W. Chen,
M. W. Wong, C. Gonzalez, and J. A. Pople, Gaussian, Inc., Pittsburgh PA, 2003.

[51] F. Zhang, J. Lan, Z.S. Zhao, Y. Yang, R.Q. Tan, W.J. Song, Removal of heavy metal ions from aqueous solution using Fe3O4-SiO2-poly(1,2-diaminobenzene) core-shell sub-micron particles, J Colloid Interf Sci, 387 (2012) 205-212.

[52] K.P. Raven, A. Jain, R.H. Loeppert, Arsenite and arsenate adsorption on ferrihydrite: Kinetics, equilibrium, and adsorption envelopes, Environ Sci Technol, 32 (1998) 344-349.

[53] A. Jain, R.H. Loeppert, Effect of competing anions on the adsorption of arsenate and arsenite by ferrihydrite, $\mathrm{J}$ Environ Qual, 29 (2000) 1422-1430.

[54] M.L. Pierce, C.B. Moore, Adsorption of Arsenite and Arsenate on Amorphous Iron Hydroxide, Water Res, 16 (1982) 1247-1253.

[55] J.A. Wilkie, J.G. Hering, Adsorption of arsenic onto hydrous ferric oxide: Effects of adsorbate/adsorbent ratios and co-occurring solutes, Colloid Surface A, 107 (1996) 97-110.

[56] T.H. Hsia, S.L. Lo, C.F. Lin, D.Y. Lee, Characterization of Arsenate Adsorption on Hydrous Iron-Oxide Using Chemical and Physical Methods, Colloid Surface A, 85 (1994) 1-7.

[57] L. Cumbal, A.K. Sengupta, Arsenic removal using polymer-supported hydrated iron(III) oxide nanoparticles: Role of Donnan membrane effect, Environ Sci Technol, 39 (2005) 6508-6515.

[58] M.M. Emara, A.S.M. Tourky, M.M. El-Moselhy, Structural modification of mordenite zeolite with $\mathrm{Fe}$ For the photo-degradation of EDTA, J Hazard Mater, 166 (2009) 514-522.

[59] M. German, H. Seingheng, A.K. SenGupta, Mitigating arsenic crisis in the developing world: Role of robust, reusable and selective hybrid anion exchanger (HAIX), Sci Total Environ, 488 (2014) 551-557. 